\title{
Dynamic Characterization of the AWT-26 Turbine for Variable Speed Operation
}

Scott M. Larwood

National Wind Technology Center

National Renewable Energy Laboratory Golden, Colorado

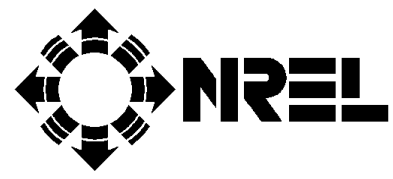

National Renewable Energy Laboratory 1617 Cole Boulevard Golden, Colorado 80401-3393

A national laboratory of the U.S. Department of Energy Managed by Midwest Research Institute for the U.S. Department of Energy under contract No. DE-AC36-83CH10093

Work performed under Task No. WE803030 July 1998 


\section{NOTICE}

This report was prepared as an account of work sponsored by an agency of the United States government. Neither the United States government nor any agency thereof, nor any of their employees, makes any warranty, express or implied, or assumes any legal liability or responsibility for the accuracy, completeness, or usefulness of any information, apparatus, product, or process disclosed, or represents that its use would not infringe privately owned rights. Reference herein to any specific commercialproduct, process, or service by trade name, trademark, manufacturer, or otherwise does not necessarily constitute or imply its endorsement, recommendation, or favoring by the United States government or any agency thereof. The views and opinions of authord expressed herein do not necessarily state or reflect those of the United States government or any agency thereof.

Available to DOE and DOE contractors from:

Office of Scientific and Technical Information (OSTI)

P.O. Box 62

Oak Ridge, TN 37831

Prices available by calling (423) 576-8401

Available to the public from:

National Technical Information Service (NTIS)

U.S. Department of Commerce

5285 Port Royal Road

Springfield, VA 22161

(703) 487-4650 


\section{Preface}

This report was prepared by Scott Larwood of the National Wind Technology Center. It describes an experiment to determine critical rotor speeds on the Advanced Wind Turbines, Inc. AWT-26/Protoype 3 for variable speed operation. The turbine was instrumented to measure accelerations and the data were reduced to determine areas of potential resonance. Critical rotor speeds were determined for incorporation into the variable speed control algorithm. 


\section{Executive Summary}

\section{Introduction}

The Advanced Wind Turbines, Inc. AWT-26 Prototype \#3 at the National Wind Technology Center (NWTC) was modified for variable speed operation. This program was in support of emerging technologies in variable speed power generation. Electronic Power Conditioning Inc. (EPC) of Corvallis, Oregon manufactured the new variable speed generation system (VSGS) for the turbine. The VSGS consisted of a doubly-fed generator and a Unipolar Series Resonant Converter (USRC).

The AWT-26 is a downwind, teetered, two-blade machine that operates at a constant 57.3-rpm rotor speed. The modification to variable speed operation allowed a rotor speed range of $32 \mathrm{rpm}$ to $62 \mathrm{rpm}$. The turbine was not originally designed for variable speed operation and the potential for operating at a resonant condition existed.

The purpose of the experiment described in this report was to measure turbine vibration response at discrete rotor speeds within the variable speed range and identify any potential resonant conditions. The converter variable speed algorithm could then be designed to avoid these resonant conditions.

\section{Approach}

The turbine was instrumented with four accelerometers. Two accelerometers were positioned to measure tower motion; the other two were placed in the nacelle to measure nacelle motion. The VSGS was then operated in constant speed mode at discrete rotor speeds over the variable speed range. Accelerometer spectra were acquired over a 10-minute averaging period with the turbine held at constant speed. Wind speed and direction data were also acquired to compare the spectra at different rotor speeds.

Harmonic peaks were plotted for each accelerometer over the rotor speed range. Natural frequencies were also plotted to determine crossings with the rotor harmonic frequencies. Rising harmonic peaks at these crossings were indications of possible resonant conditions.

\section{Results}

The reduced accelerometer data showed potential resonant conditions at $32 \mathrm{rpm}, 38-40 \mathrm{rpm}, 48 \mathrm{rpm}$, and $52 \mathrm{rpm}$. It was determined that the variable speed algorithm be designed to avoid $32 \mathrm{rpm}, 39 \mathrm{rpm}$, and 48 $\mathrm{rpm}$ within a $\pm 1 \mathrm{rpm}$ range. The crossing at $52 \mathrm{rpm}$ was not as severe as the other critical speeds and avoiding this speed would significantly impact the variable speed operation.

Another conclusion from the experiment was that the tower accelerometer data were not as useful as the nacelle accelerometer data. For similar turbine designs, this could reduce the cost of like experiments and turbine vibration monitoring equipment. 


\section{Contents}

Introduction $\quad \underline{\text { Page }}$

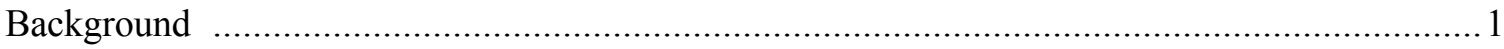

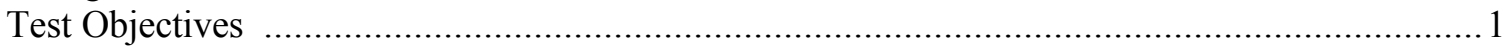

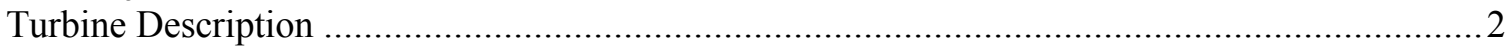

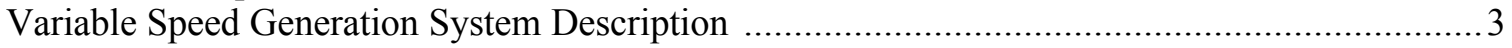

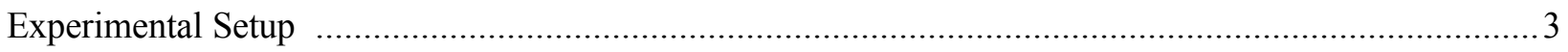

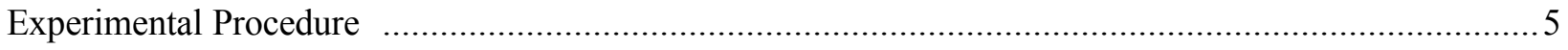

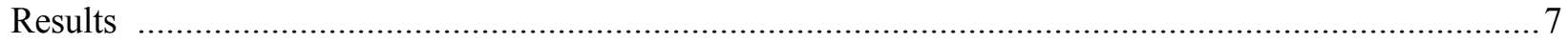

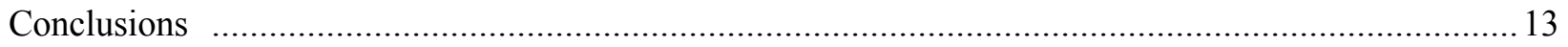

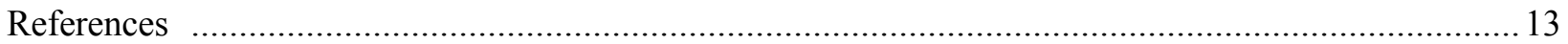

\section{List of Figures}

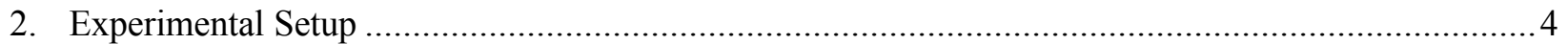

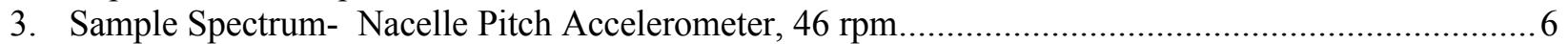

4. Nacelle Yaw Accelerometer Harmonic Peaks ................................................................. 8

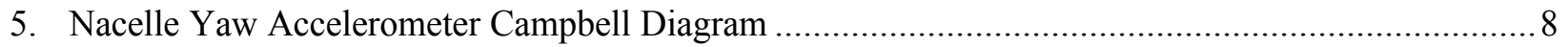

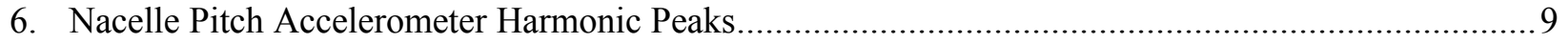

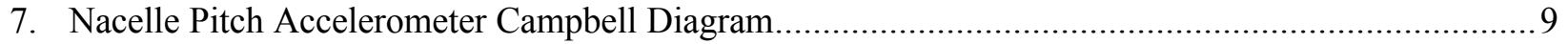

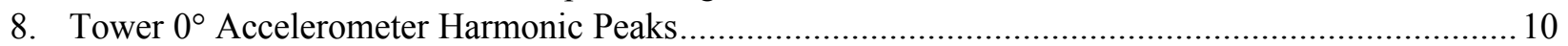

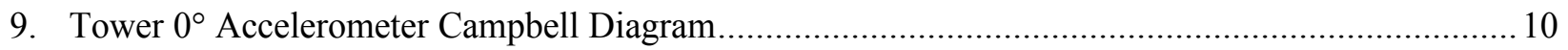

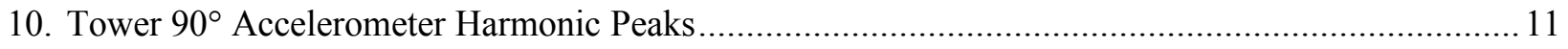

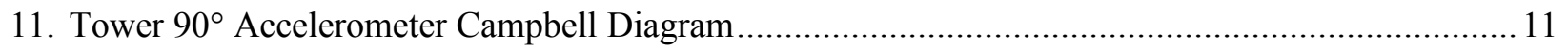

\section{List of Tables}

1. Campbell Diagram Natural Frequency Crossings $\quad \underline{\text { Page }}$ 
TP-500-24919

\section{Introduction}

\section{Background}

The National Wind Technology Center (NWTC) has embarked on a program to provide support for industry partners and emerging technology that may have significant impact on the cost of energy for wind turbines. This program is called the Next Generation Innovative Subsystem (NGIS) program. One of the subcontracts awarded in this program was to Electronic Power Conditioning, Inc. (EPC) of Corvallis, Oregon. EPC developed a Variable Speed Generation Subsystem (VSGS) incorporating a doubly-fed generator and a Unipolar Series Resonant Converter (USRC). The doubly-fed generator reduced the converter power rating compared to the power electronics for an induction design generator. The USRC utilized a quasi-resonant power circuit that resulted in soft switching of the converter semiconductors. Soft switching reduces stresses on the semiconductor devices, reduces switching losses, and allows the converter to operate at higher modulation frequencies. Additional benefits are lower voltage transients, reduced electromagnetic interference, and lower harmonic distortion at the input and output.

EPC originally collaborated with Zond Energy Systems as part of the NGIS program, but tests were abandoned as Zond moved towards development of larger turbines. It was decided that EPC would build a converter to be tested at the NWTC site, utilizing the AWT-26 Prototype \#3 built by Advanced Wind Turbines, Inc. in Seattle, Washington. The AWT-26 is a downwind, two-blade teetered rotor with a $275-\mathrm{kW}$ power rating. Although it was not expected that converting this constant speed turbine to variable speed would show substantial improvements in energy capture, we felt the experience gained in field testing the VSGS would be worth the effort towards the development of larger-scale systems. In addition to field testing the VSGS, the turbine could be used as a test bed for comparative studies in acoustics and aerodynamics of variable-speed operation.

Because the turbine operated over a speed range that crossed some of the system natural frequencies, a test was developed to measure the turbine dynamic response under operation at discrete operating speeds. From these measurements the critical operating speeds were identified and the VSGS control algorithm was modified to avoid these speeds. The description of these tests (termed "Dynamic Characterization Tests") and the results are the subject of this report.

\section{Test Objectives}

The objective of the Dynamic Characterization of the AWT-26/P3 was to determine which rotor speeds to avoid for variable speed operation. The critical rotor speeds were determined by measurement of turbine vibration over the variable speed range. 


\section{Turbine Description}

The AWT-26/P3 is located at site 3.2 at the NWTC (Figure 1). The turbine specifications are listed below:

- $275 \mathrm{~kW}$ rated power

- 26.2-meter rotor diameter

- Two-blade stall-controlled teetered rotor with aerodynamic tip brakes

- Downwind free-yaw rotor

- Planetary gearbox (26.07:1 ratio)

- 32-62 rpm rotor speed range

- Disc brake on high speed shaft

- 80-foot tubular "stiff" tower

- $5 \mathrm{~m} / \mathrm{s}$ cut-in, $23 \mathrm{~m} / \mathrm{s}$ cut-out wind speeds

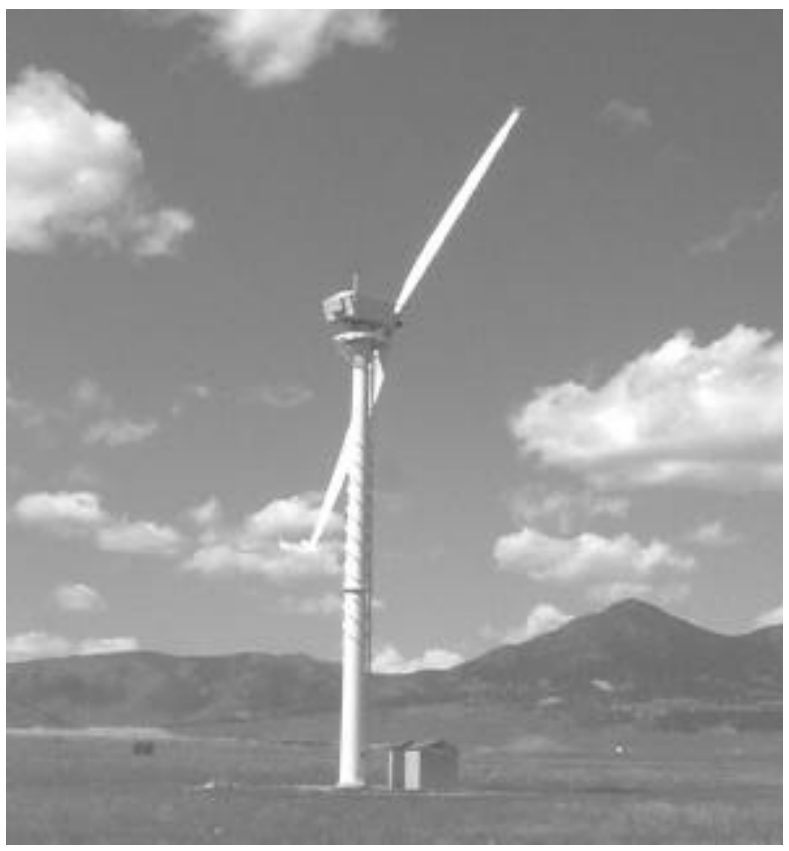

Figure 1. AWT-26/P3 Turbine at the NWTC Site 3.2

The meteorology tower for Site 3.2 is located approximately two rotor diameters from the turbine in the prevailing wind direction at $292^{\circ}$ North. There are no obstructions to the tower or turbine in this prevailing wind direction for 18.75 rotor diameters.

The turbine was modified from the original prototype for incorporation of the VSGS. The doubly-fed generator was longer and protruded from the nacelle so an enclosure was installed on the rear of the nacelle. The gearbox was replaced with a lower gear ratio model in order to reduce the size and cost of the EPC converter. Changes were also made in the electrical and control system because the converter was now responsible for control of the generator.

A description of the turbine dynamics can be found in reference 1 and reference 2 . Reference 1 states "[t]he natural frequencies of the operating machine are not the same as those of the stationary structure 
due to the effects of rotation which, in this case, include the periodic nature of the support conditions." This periodic nature of the support conditions results in families of peaks in the operating spectrum, with members of the families separated by $2 / \mathrm{rev}$ ( 2.0 times the rotor speed).

\section{Variable Speed Generation System}

The VSGS incorporated a converter and generator. The converter was housed in a shed off to the side of the turbine tower (see Figure 1). Power and instrumentation cables were routed through the converter enclosure and out to another shed which housed the electrical panels and turbine controller.

The converter was primarily intended to operate in variable speed, but for the purposes of this test and for the initial checkout phase, the converter was run in constant-speed mode. In this mode the generator was run as a synchronous generator with the generator rotor frequency controlled by the converter. The generator speed can be set with the operator control panel on the front of the converter cabinet. Also in this mode the converter had an electronic damping algorithm that used variations in stator reactive power to adjust the rotor frequency slightly.

For variable speed operation, the converter used field-orientated control. The converter supplied a generator torque reference (and thus power) based on the rotor speed. The torque was proportional to the stator active power and the converter adjusted the generator rotor current, phase and amplitude to provide the correct torque. The converter was provided a rpm versus power schedule via the front panel.

In order to avoid critical rpm setpoints (identified by the Dynamic Characterization Tests), the power versus rpm schedule for the converter was set to constant torque over the range of the critical speed. This torque will be lower than the power available in the turbine rotor, thus the turbine will accelerate away from the critical speed. With this scheme there is no guarantee that the rotor will not dwell within the critical speed, but the time spent in this range will be minimized.

\section{Experimental Setup}

Figure 2 shows a representation of the experimental setup. The turbine was instrumented with four accelerometers for the experiment. Two accelerometers were placed on one mounting block in the nacelle; one measured lateral yawing motion and the other measured pitching motion. The mounting location was located approximately 52 inches downwind and 6 inches left of the center of the yaw bearing and 22 inches below the rotor shaft axis. It was expected that the nacelle pitching motion would produce the highest signals. The other two accelerometers were located on one mounting block at the upper tower flange behind the top of the ladder. One accelerometer was aligned to measure the tower motion in the prevailing wind direction; the other was aligned $90^{\circ}$ to this direction to measure lateral tower motion. All accelerometers were PCB® Piezotronics, model \#Q353B34. 


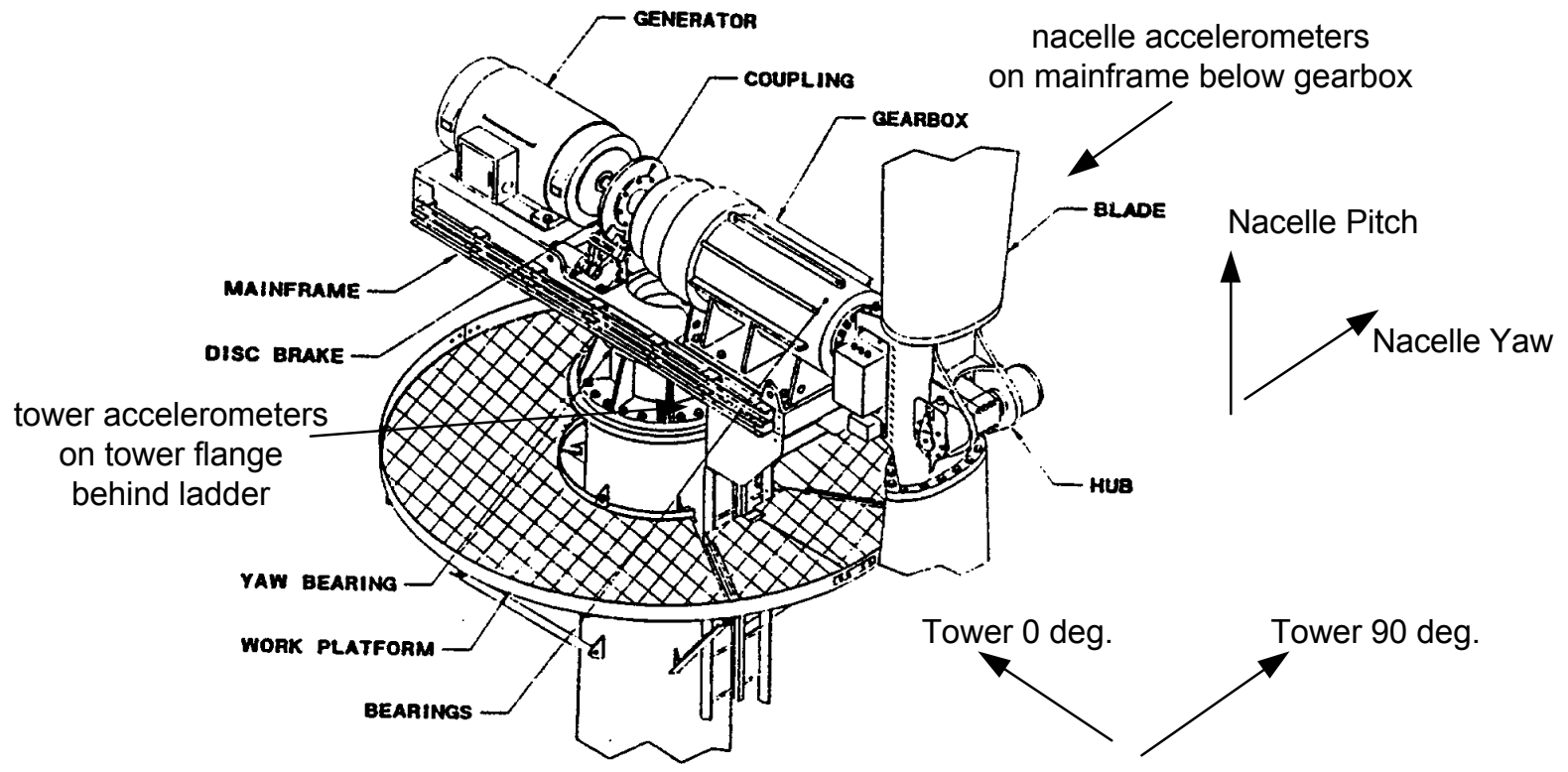

(4)- $250 \mathrm{ft}$. lengths RG-58 Cable

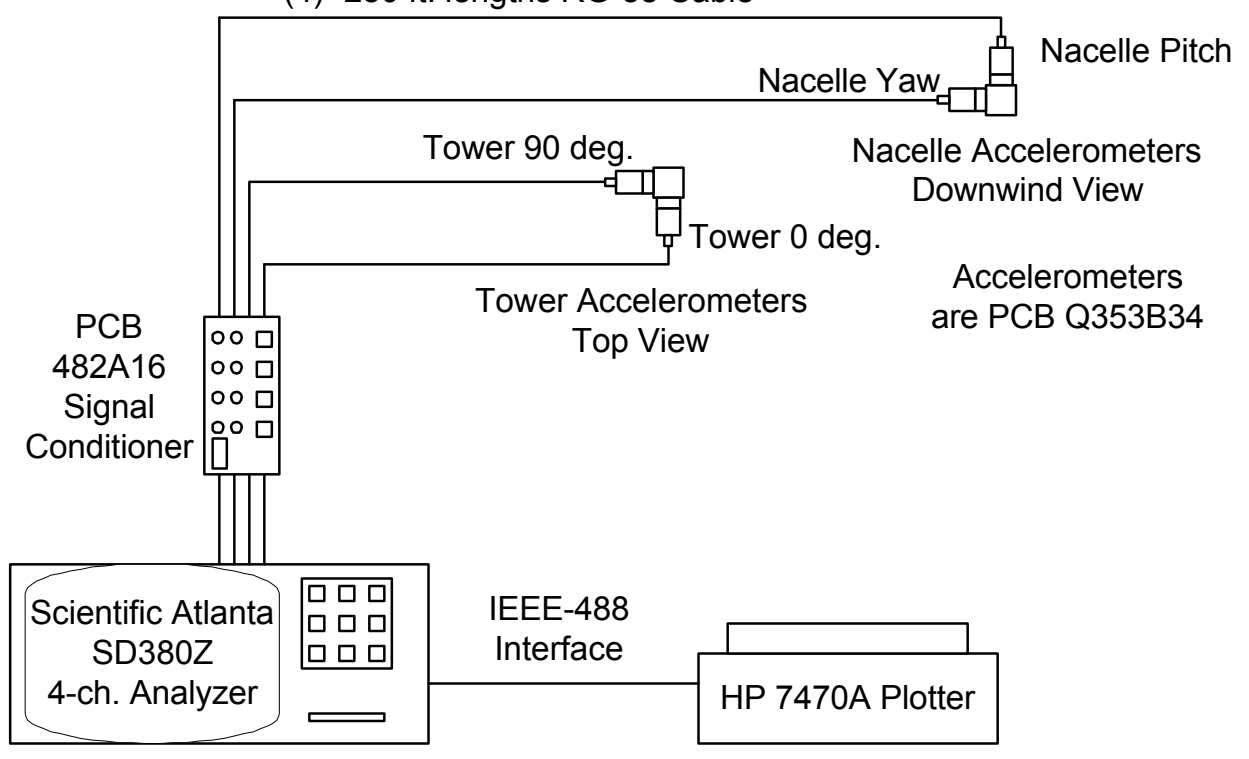

Figure 2. Experimental Setup 
The cables for the nacelle accelerometers were routed through the yaw bearing with a cable droop to allow for nacelle rotation and through a door in the tower top. From the door, the nacelle cables joined the tower accelerometer cables. All cables were then routed down the side of the ladder and into the shed next to the turbine that housed the EPC converter. The cables were connected to a 4-channel ICP (Integrated Circuit Piezoelectric) PCB ${ }^{\circledR}$ Signal Conditioner model \#482A16. The accelerometer signals were then connected to a Scientific Atlanta SD380 Four-channel Dynamic Signal Analyzer to measure the frequency spectra. The analyzer was configured as follows:

- $10 \mathrm{~Hz}$ frequency range (chosen to record up to $12 /$ rev harmonic)

- 400 line Fast Fourier Transform (FFT) Resolution

- Hanning FFT Weighting

- $50 \%$ Overlap Processing

- Linear Averaging

- 10-minute averaging period

The analyzer had a 3-1/2 inch floppy drive for storing accelerometer spectra. The spectra were periodically printed to a HP plotter with a list of the 10 highest peaks for data analysis. Wind speed and direction data were measured at hub height on the meteorology tower located two rotor diameters upwind of the turbine in the prevailing wind direction $\left(292^{\circ} \mathrm{N}\right)$. The data were sampled at $1 \mathrm{~Hz}$ and recorded at 1-minute averages using a Campbell CR10X datalogger. The 1-minute averages were then averaged over 10 -minutes to provide wind speed and direction for spectra 10-minute averages.

\section{Experimental Procedure}

The turbine was operated at constant speed from the operator terminal on the front panel of the EPC converter. The speed range was varied between 32-62 rpm in steps of $2 \mathrm{rpm}$. Two 10-minute sets of data were taken at each rpm setpoint. Later in the test period, the test matrix was reduced to a peak rotor speed of $58 \mathrm{rpm}$ because variable speed operation was not expected to exceed this value.

Comparison was made between accelerometer spectra that were recorded at approximately the same 10-minute average wind speed. Initially, data were taken at wind speeds below $6 \mathrm{~m} / \mathrm{s}$, but the amplitude of the vibration was an order of magnitude lower compared to data taken at an average of $9 \mathrm{~m} / \mathrm{s}$. Nacelle precession (yaw tracking) was also a problem at the lower wind speeds. Therefore, a wind speed of $9 \mathrm{~m} / \mathrm{s}$ was chosen for comparison. This also kept the peak power below the converter rating at the higher rpm setpoints.

After completion of each 10-minute averaging period, the four accelerometer spectra were saved to the SD-380 floppy disk. Later the spectra were retrieved from disk and a total of 10 markers were placed at the spectral peaks. The spectra and marker list were then plotted to hard copy. Figure 3 shows a scanned image of a sample spectrum. This spectrum was generated from the nacelle pitch accelerometer at a rotor speed of $46 \mathrm{rpm}$ and 10-minute average wind speed of $9.75 \mathrm{~m} / \mathrm{s}$. 


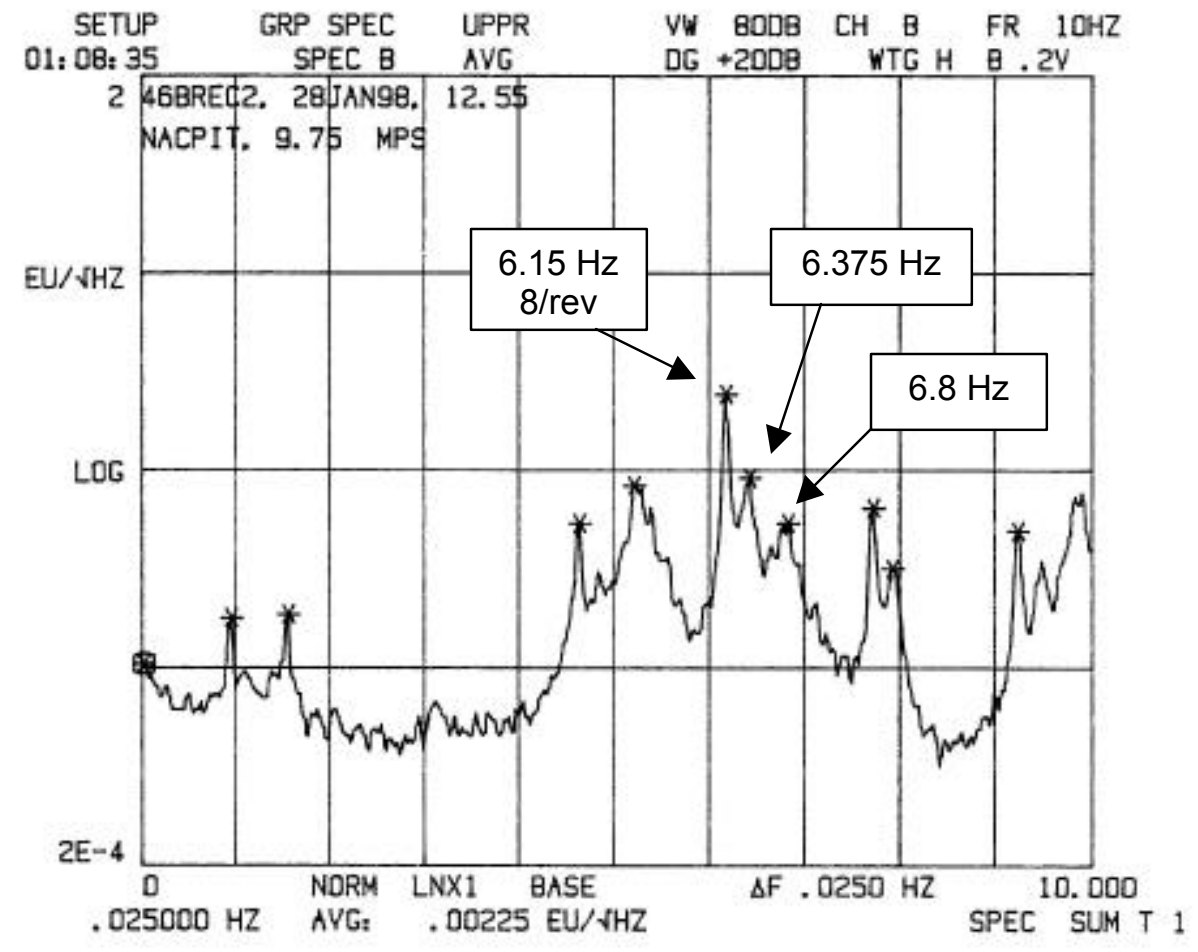

Figure 3. Sample Spectrum- Nacelle Pitch Accelerometer, 46 rpm 


\section{Results}

The spectra for the four accelerometers and 13 discrete rotor speeds (32-58 rpm in increments of 2-rpm) were plotted for comparison. The data were further reduced by comparing the data set from each rpm closest to a wind speed of $9 \mathrm{~m} / \mathrm{s}$ for the 10-minute average. The peaks from each spectrum were separated into harmonic and off-harmonic multiples of rotor speed. These peaks can be seen in Figure 3 for the nacelle pitch accelerometer. For example, there are three peaks between $6 \mathrm{~Hz}$ and $7 \mathrm{~Hz}$. The first peak is at $6.15 \mathrm{~Hz}$, which corresponds to the $8 / \mathrm{rev}$-rotor harmonic. The next two peaks are off-harmonic frequencies at $6.375 \mathrm{~Hz}$ and $6.8 \mathrm{~Hz}$.

The harmonic peaks for each accelerometer were then plotted over the rpm range. These plots are shown in Figures 4, 6, 8 and 10. Only even rotor harmonics were measurable and the maximum harmonic plotted was 12/rev (up to $50 \mathrm{rpm}$ rotor speed). Rising amplitude in these plots was an indication of potential resonance.

Further indications of resonant conditions were determined by plotting the off-harmonic peaks onto Campbell diagrams. These are shown in Figures 5, 7, 9, and 11 for each accelerometer. Note that only the natural frequency peaks found consistently in the data were plotted. The Campbell diagram shows frequency versus rotor speed and includes lines of constant rotor harmonics. The natural frequency lines were separated into two families as described in reference 1 . The lines in each family are separated by 2-times the rotor frequency. A crossing of a natural frequency line and a rotor harmonic represents a potential resonant condition. The severity of these crossings can be judged by looking at the plots of the harmonic peaks. 


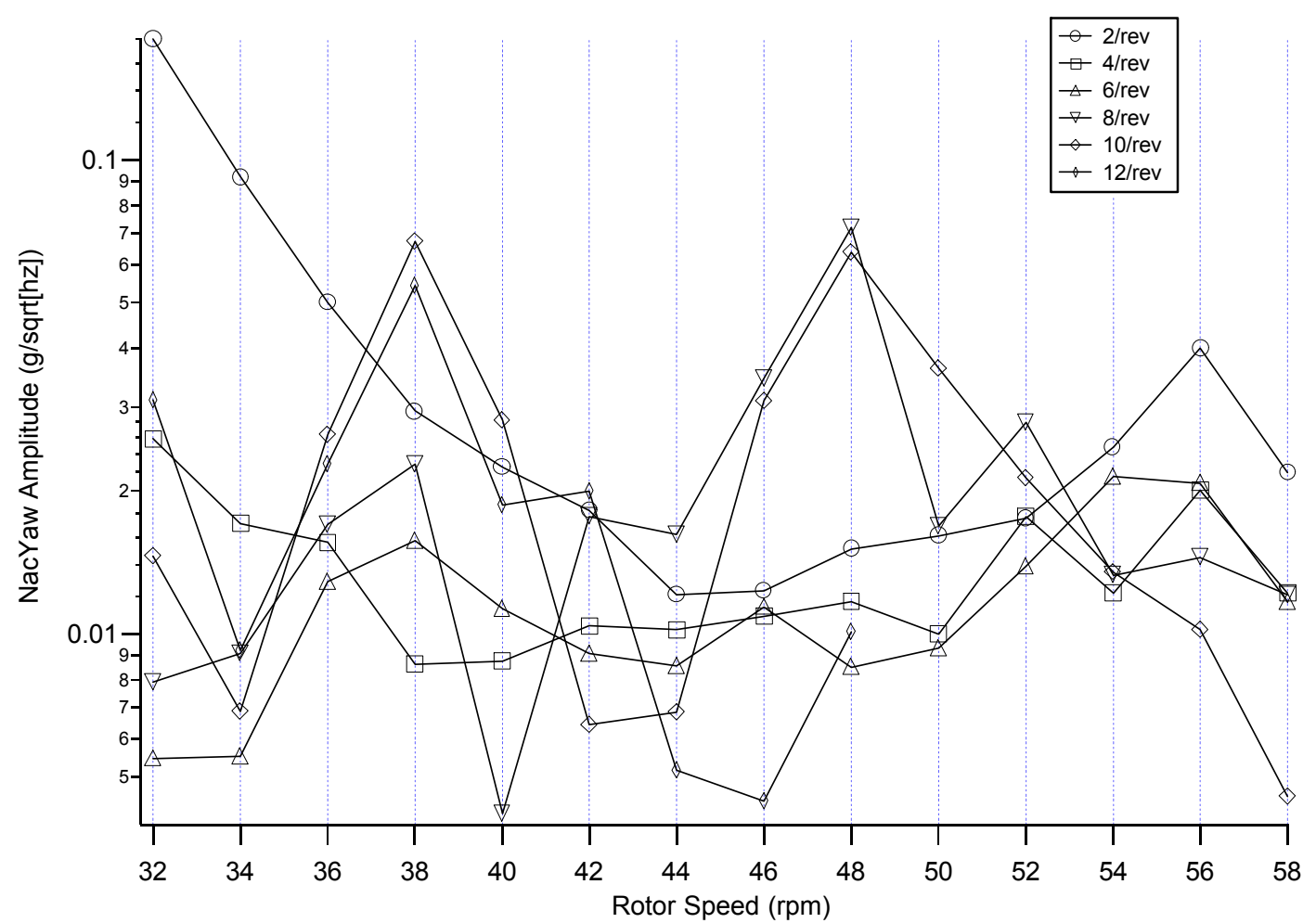

Figure 4. Nacelle Yaw Accelerometer Harmonic Peaks

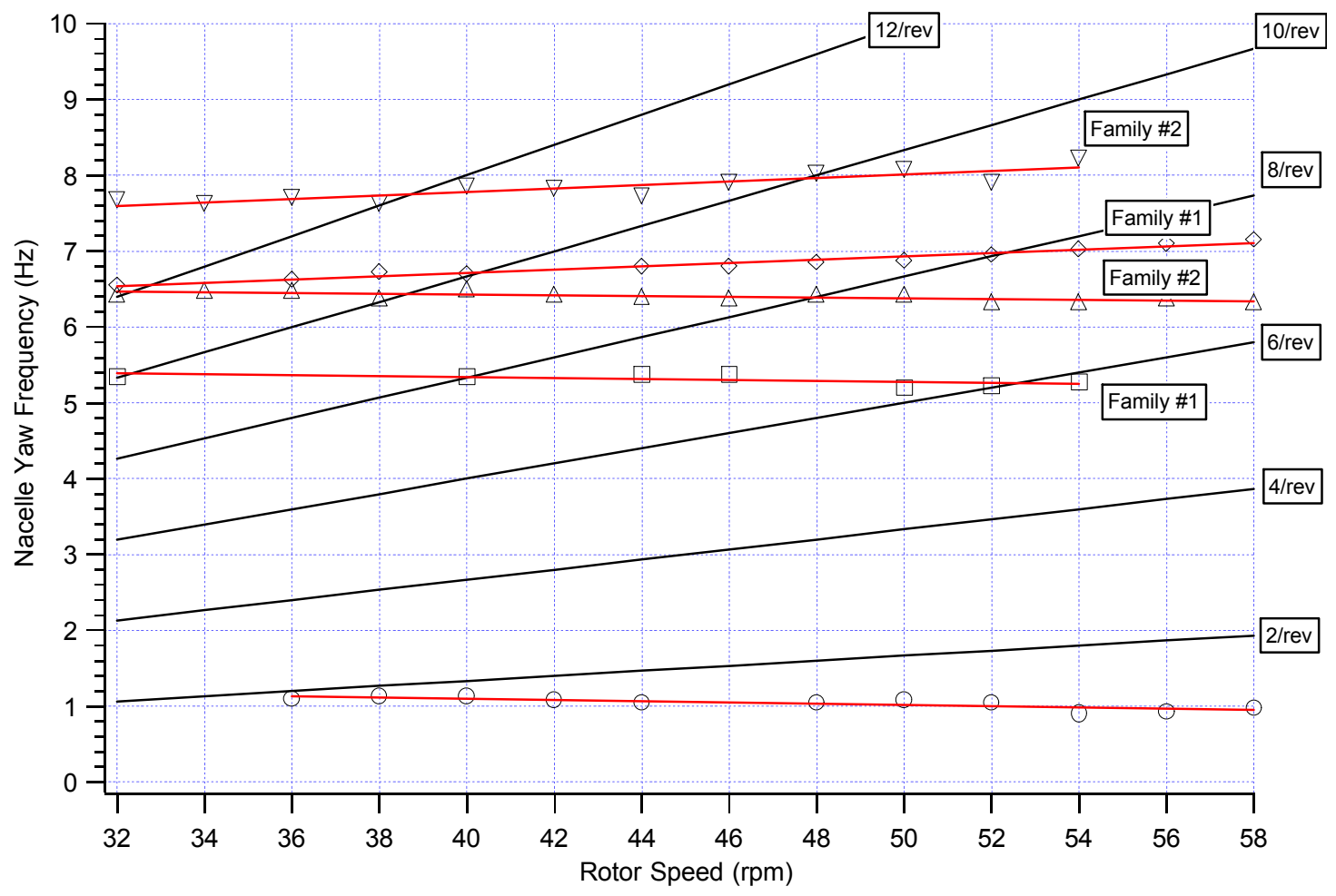

Figure 5. Nacelle Yaw Accelerometer Campbell Diagram 
TP-500-24919

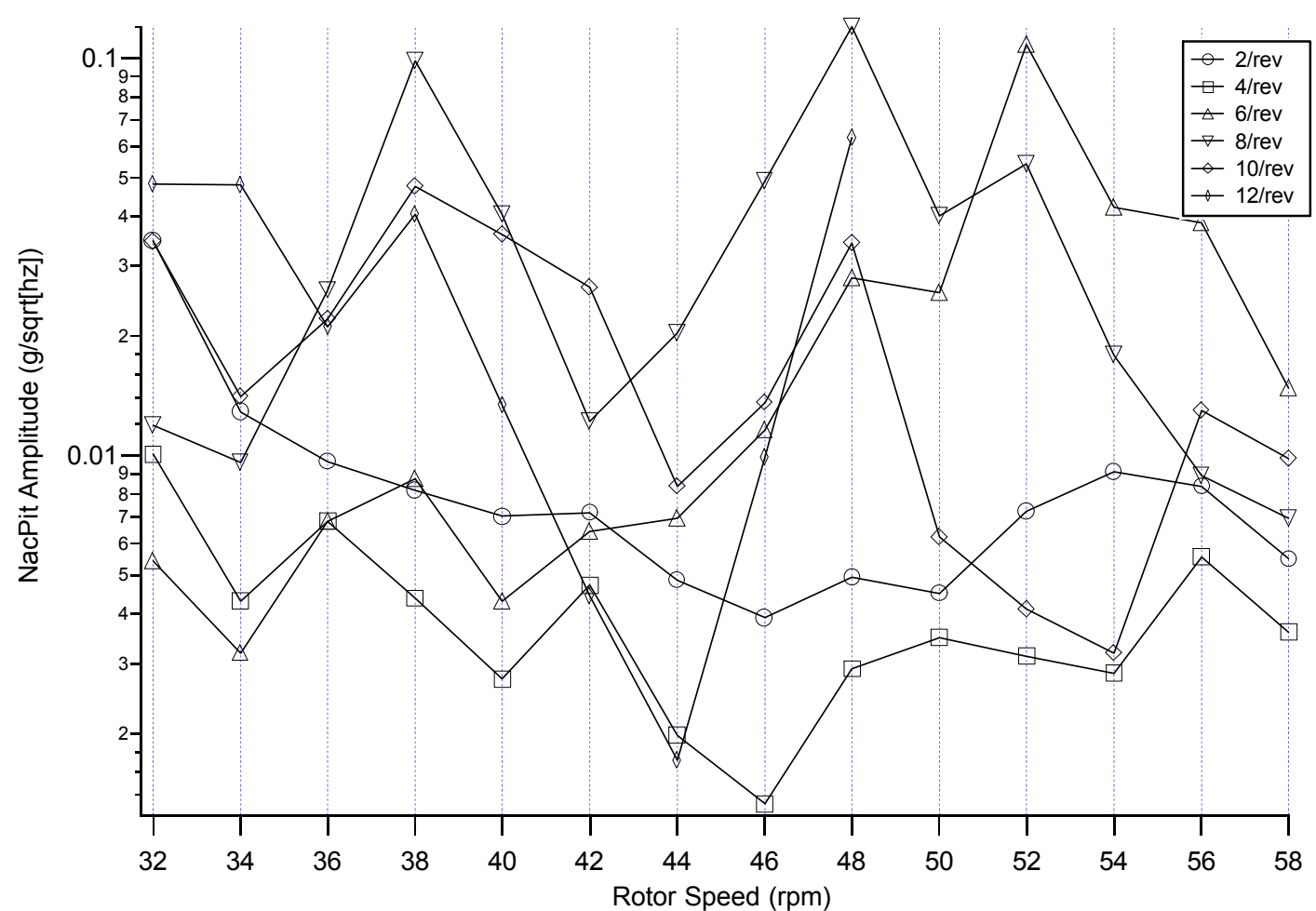

Figure 6. Nacelle Pitch Accelerometer Harmonic Peaks

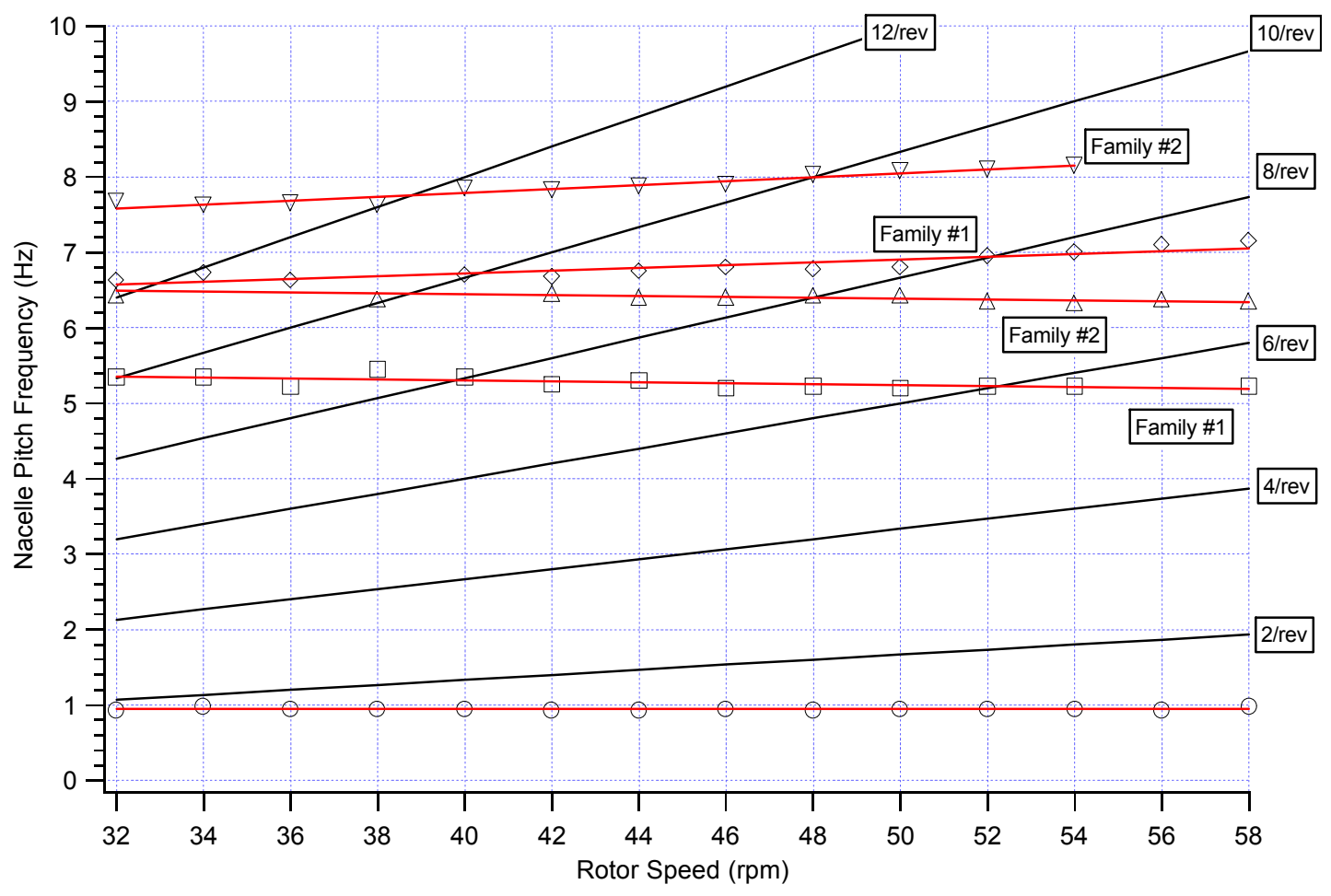

Figure 7. Nacelle Pitch Accelerometer Campbell Diagram 


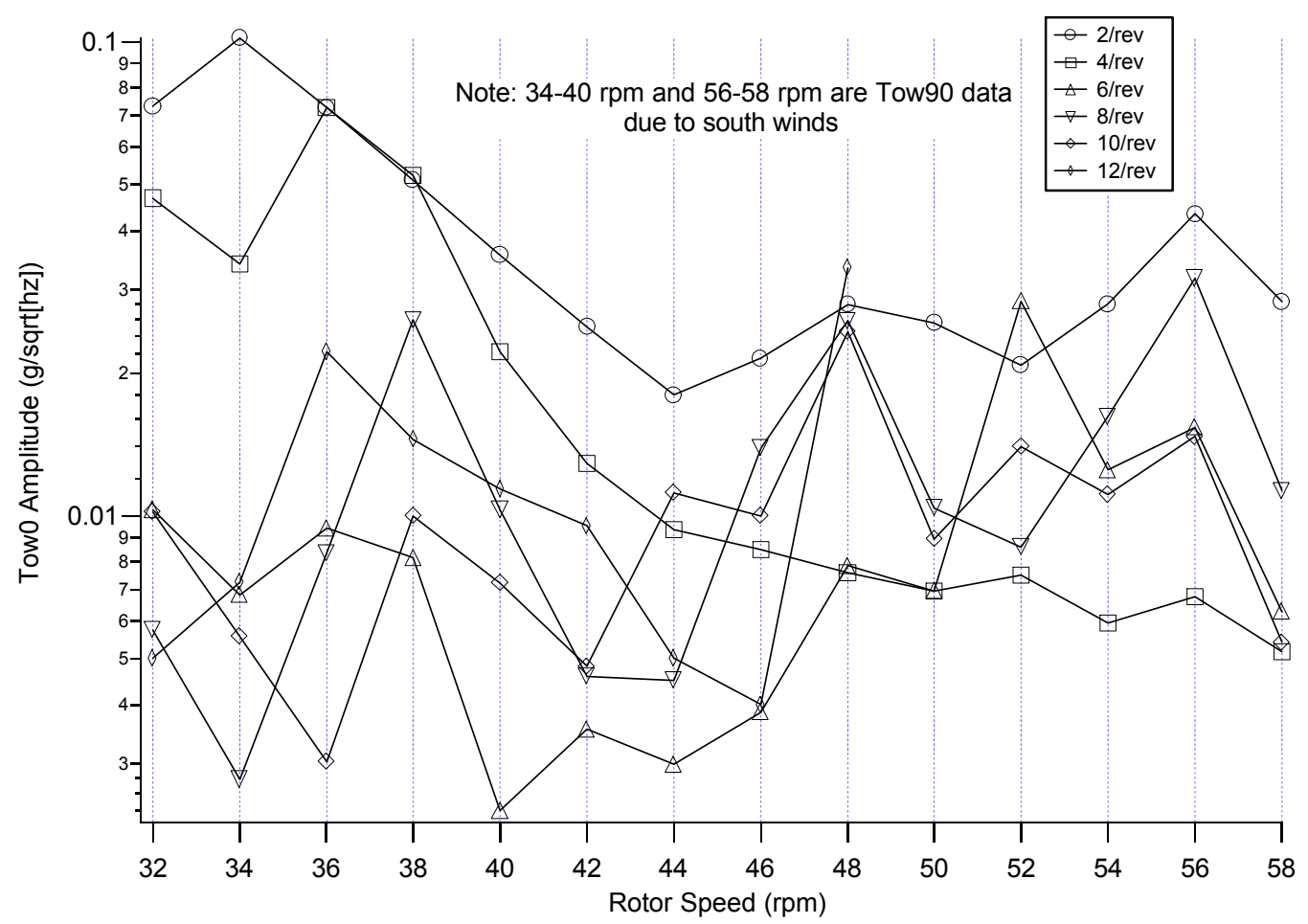

Figure 8. Tower $0^{\circ}$ Accelerometer Harmonic Peaks

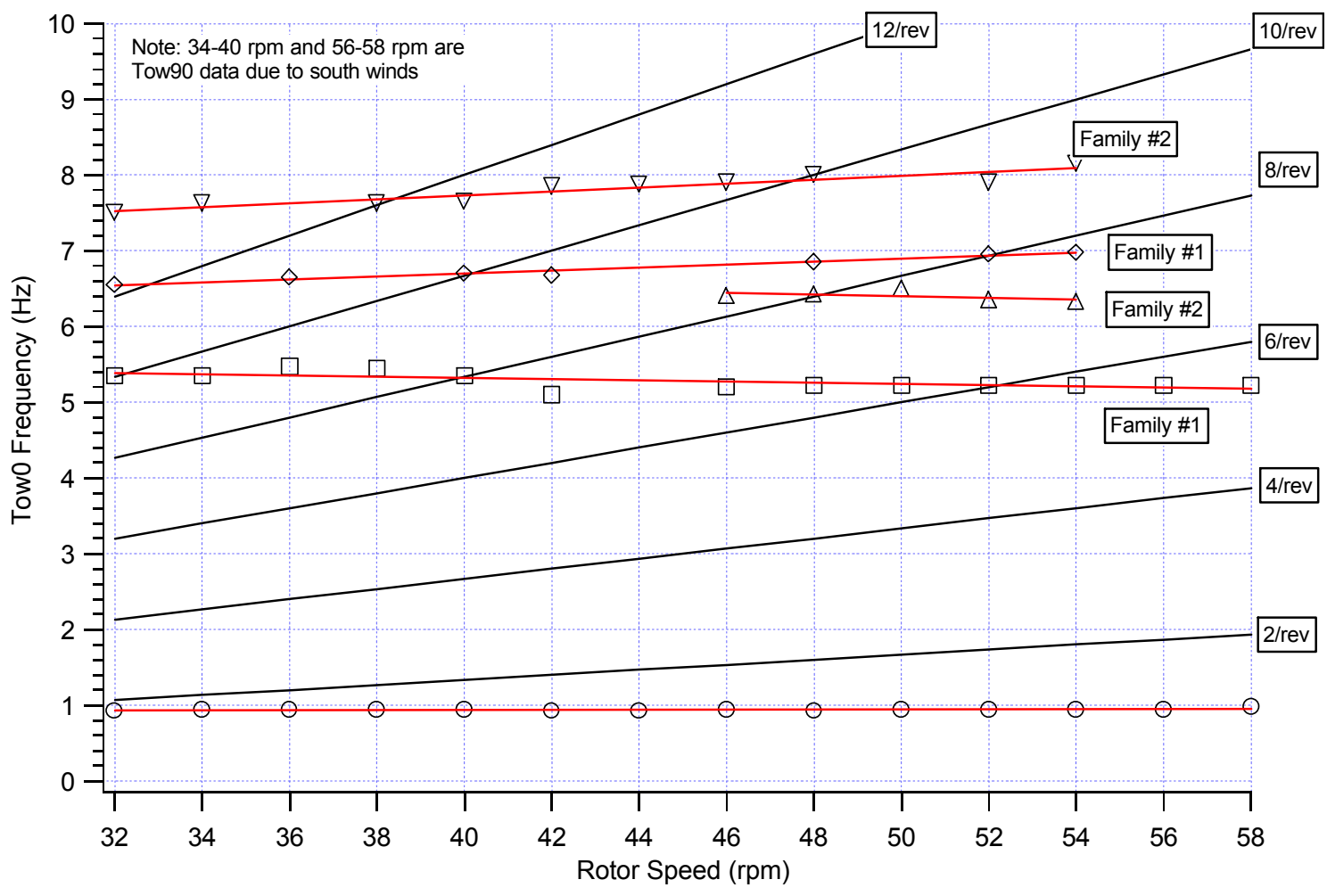

Figure 9. Tower $0^{\circ}$ Accelerometer Campbell Diagram 


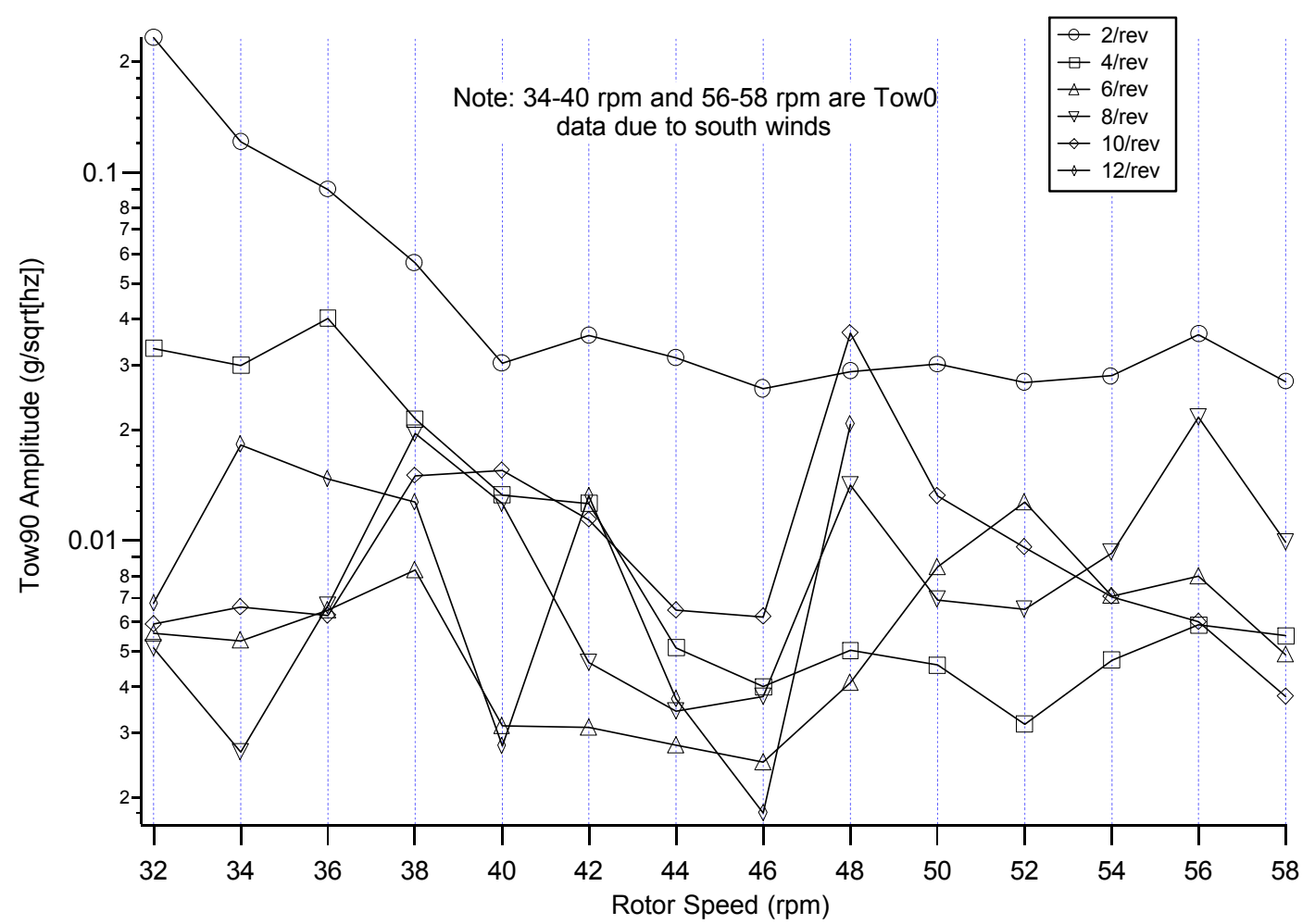

Figure 10. Tower $90^{\circ}$ Accelerometer Harmonic Peaks

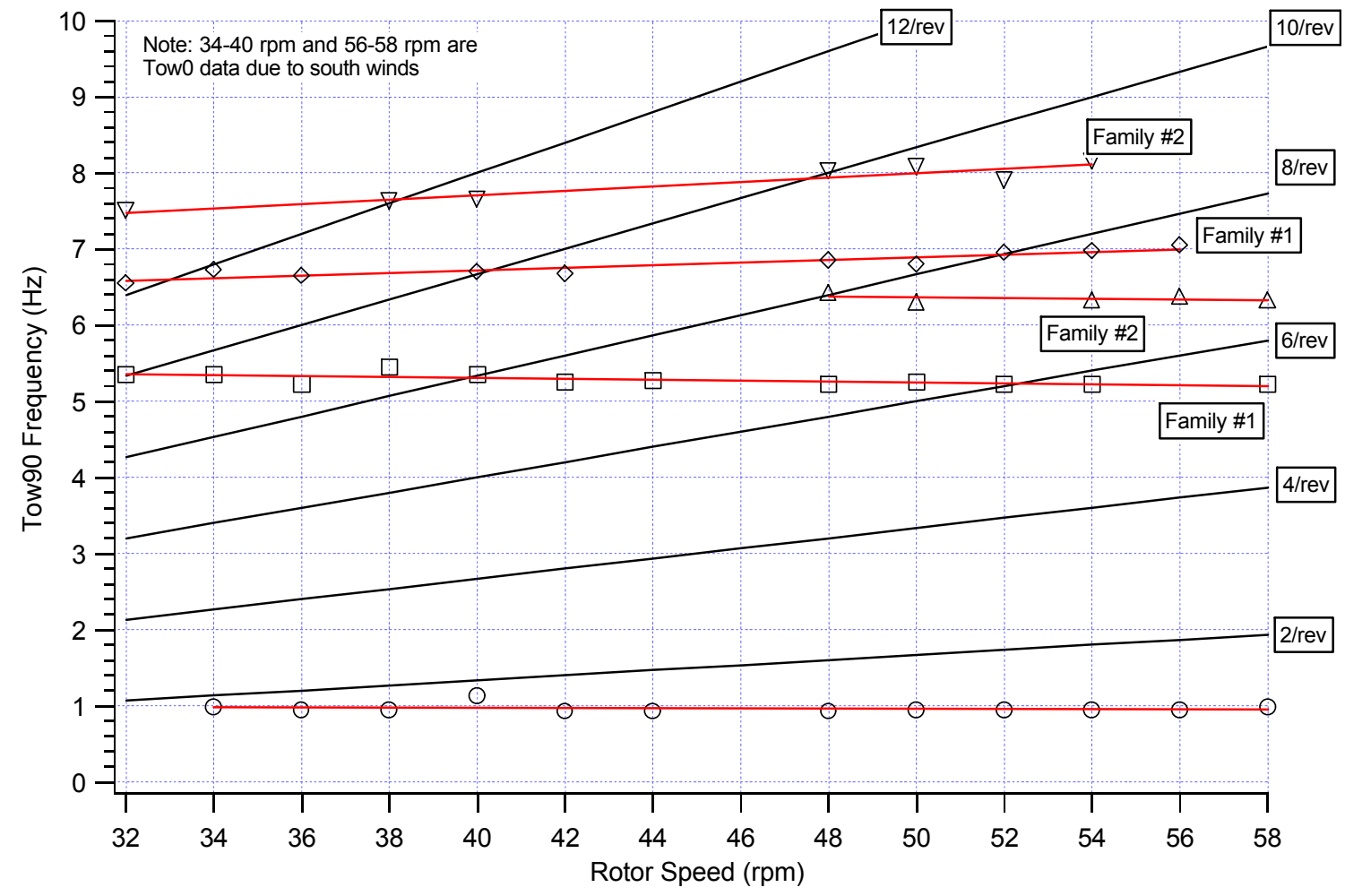

Figure 11. Tower $90^{\circ}$ Accelerometer Campbell Diagram 
Table 1 lists the natural frequency crossings shown in the Campbell Diagrams for each accelerometer. All signals showed crossings at the same rotor speeds. The multiple crossings in the 38-40 rpm range and at $48 \mathrm{rpm}$ were the most predominant, especially in the nacelle pitch accelerometer peaks. The crossing at $52 \mathrm{rpm}$ showed less harmonic peaks than at the $38-40 \mathrm{rpm}$ and $48 \mathrm{rpm}$ ranges. We decided not to avoid $52 \mathrm{rpm}$ in the VSGS control algorithm because the power changed rapidly in this range and the variable speed experiments would have been significantly impacted.

Table 1. Campbell Diagram Natural Frequency Crossings

\begin{tabular}{|c|c|c|}
\hline Accelerometer Signal & Rotor Speed at Crossing (rpm) & Harmonic at Crossing (/rev) \\
\hline \multirow{4}{*}{ Nacelle Yaw } & 32 & 2 (potential), 10 and 12 \\
\cline { 2 - 3 } & $38-40$ & 8,10, and 12 \\
\cline { 2 - 3 } & 48 & 8 and 10 \\
\cline { 2 - 3 } & 52 & 6 and 8 \\
\hline \multirow{5}{*}{ Nacelle Pitch } & 32 & 2 (potential), 10 and 12 \\
\cline { 2 - 3 } & $38-40$ & 8,10, and 12 \\
\cline { 2 - 3 } & 48 & 8 and 10 \\
\hline \multirow{5}{*}{ Tower $0^{\circ}$} & 52 & 6 and 8 \\
\cline { 2 - 3 } & 32 & 8 (potential) and 10 \\
\cline { 2 - 3 } & $38-40$ & 8 and 10 \\
\cline { 2 - 3 } & 48 & 6 and 8 \\
\hline Tower $90^{\circ}$ & 52 & 2 (potential) and 10 \\
\cline { 2 - 3 } & 32 & 8,10, and 12 \\
\cline { 2 - 3 } & $38-40$ & 8 and 10 \\
\cline { 2 - 3 } & 48 & 6 and 8 \\
\hline
\end{tabular}

Although the test data indicate potential resonance at several rotor speeds, unusual vibratory motion was observed only at $32 \mathrm{rpm}$. There appeared to be a coupling between nacelle yaw motion and tower lateral bending. Evidence of this behavior can be seen in Figures 4 and 10 with a rising 2/rev peak in the nacelle yaw accelerometer and tower $90^{\circ}$ accelerometer. This is probably associated with resonance between the fundamental tower lateral mode and $2 /$ rev excitation. 


\section{Conclusions}

It was concluded from the data that the rotor speeds of $32 \mathrm{rpm}, 39 \mathrm{rpm}$, and $48 \mathrm{rpm}$ should be avoided with a $\pm 1 \mathrm{rpm}$ range. Tower motions were a concern at $32 \mathrm{rpm}$ and multiple natural frequency crossings in the Campbell diagrams were shown at $38 \mathrm{rpm}$ to $40 \mathrm{rpm}$ and at $48 \mathrm{rpm}$. A crossing was also found at $52 \mathrm{rpm}$, but was determined to be less severe than those at $39 \mathrm{rpm}$ and $48 \mathrm{rpm}$. Avoiding $52 \mathrm{rpm}$ would significantly impact the variable speed experiments planned for the turbine.

The nacelle accelerometer data were of considerably more use than the tower data, and any future tests could rely on nacelle data only. This can have implications for acceleration monitoring systems and future dynamic characterization tests with turbines of similar design. A two-channel system greatly reduces the instrumentation cost.

\section{References}

1. Malcolm, D. J.; Wright, A. D., "The Use of ADAMS to Model the AWT-26 Prototype," Presented at the $13^{\text {th }}$ ASME Wind Energy Symposium, Energy Sources Technology Conference, New Orleans, June 1994.

2. Malcolm, D. J.; James, G. H., "Identification of Natural Operating Modes of HAWTs from Modeling Data," Proceedings of the ASME Wind Energy Symposium, Energy Week Conference and Exhibition, Houston, January 1996. 
Public reporting burden for this collection of information is estimated to average 1 hour per response, including the time for review ing instructions, searching existing data sources, gathering and maintaining the data needed, and completing and reviewing the collection of information. Send comments regarding this burden estimate or any other aspect of this collection of information, including suggestions for reducing this burden, to Washington Headquarters Services, Directorate for Information Operations and Reports, 1215 J efferson Davis Highway, Suite 1204, Arlington, VA 22202-4302, and to the Office of Management and Budget, Paperw ork Reduction Project (0704-0188), Washington, DC 20503.

\begin{tabular}{|l|l|l|l|}
\hline 1. & $\begin{array}{c}\text { 2. REPORT DATE } \\
\text { July } 1998\end{array}$ & $\begin{array}{l}\text { 3. REPORT TYPE AND DATES COVERED } \\
\text { Technical Report }\end{array}$ \\
\hline
\end{tabular}

4. TITLE AND SUBTITLE

Dynamic Characterization of the AWT-26 Turbine for Variable-Speed Operation

6. $\operatorname{AUTHOR}(S)$

Scott M. Larw ood

7. PERFORMING ORGANIZATION NAME(S) AND ADDRESS(ES)

National Wind Technology Center

National Renewable Energy Laboratory

1617 Cole Blvd.

Golden, CO 80401-3393

9. SPONSORING/MONITORING AGENCY NAME(S) AND ADDRESS(ES)

National Renew able Energy Laboratory

1617 Cole Blvd.

Golden, CO 80401-3393
5. FUNDING NUMBERS

C:

TA: WE803030

8. PERFORMING ORGANIZATION REPORT NUMBER

11. SUPPLEMENTARY NOTES

12a. DISTRIBUTION/AVAILABILITY STATEMENT

National Technical Information Service

U.S. Department of Commerce

5285 Port Royal Road

Springfield, VA 22161 12b. DISTRIBUTION CODE

UC-1213

13. ABSTRACT (Maximum 200 words)

The report describes an experiment to determine critical rotor speeds on the Advanced Wind Turbines, Inc., AWT-26/Prototype 3 for variable speed operation. The turbine was instrumented to measure accelerations and the data were reduced to determine areas of potential resonance. Critical rotor speeds were determined for incorporation into the variable speed control algorithm.

\begin{tabular}{|c|c|c|c|c|c|c|c|}
\hline 14. & SUBJ ECT TERMS & & & & & 15. & NUMBER OF PAGES \\
\hline & renew able eners & nerg & ariable speed ger & win & bine; wind pow er & 16. & PRICE CODE \\
\hline 17. & $\begin{array}{l}\text { SECURITY } \\
\text { CLASSIFICATION } \\
\text { OF REPORT } \\
\text { Unclassified }\end{array}$ & 18. & $\begin{array}{l}\text { SECURITY } \\
\text { CLASSIFICATION } \\
\text { OF THIS PAGE } \\
\text { Unclassified }\end{array}$ & & $\begin{array}{l}\text { SECURITY } \\
\text { CLASSIFICATION } \\
\text { OF ABSTRACT } \\
\text { Unclassified }\end{array}$ & 20. & $\begin{array}{l}\text { LIMITATION OF ABSTRACT } \\
\text { UL }\end{array}$ \\
\hline
\end{tabular}

NSN 7540-01-280-5500

Standard Form 298 (Rev. 2-89)

Prescribed by ANSI Std. Z39-18 